\title{
Open peroral endoscopic myotomy for achalasia with sigmoid-shaped esophagus
}

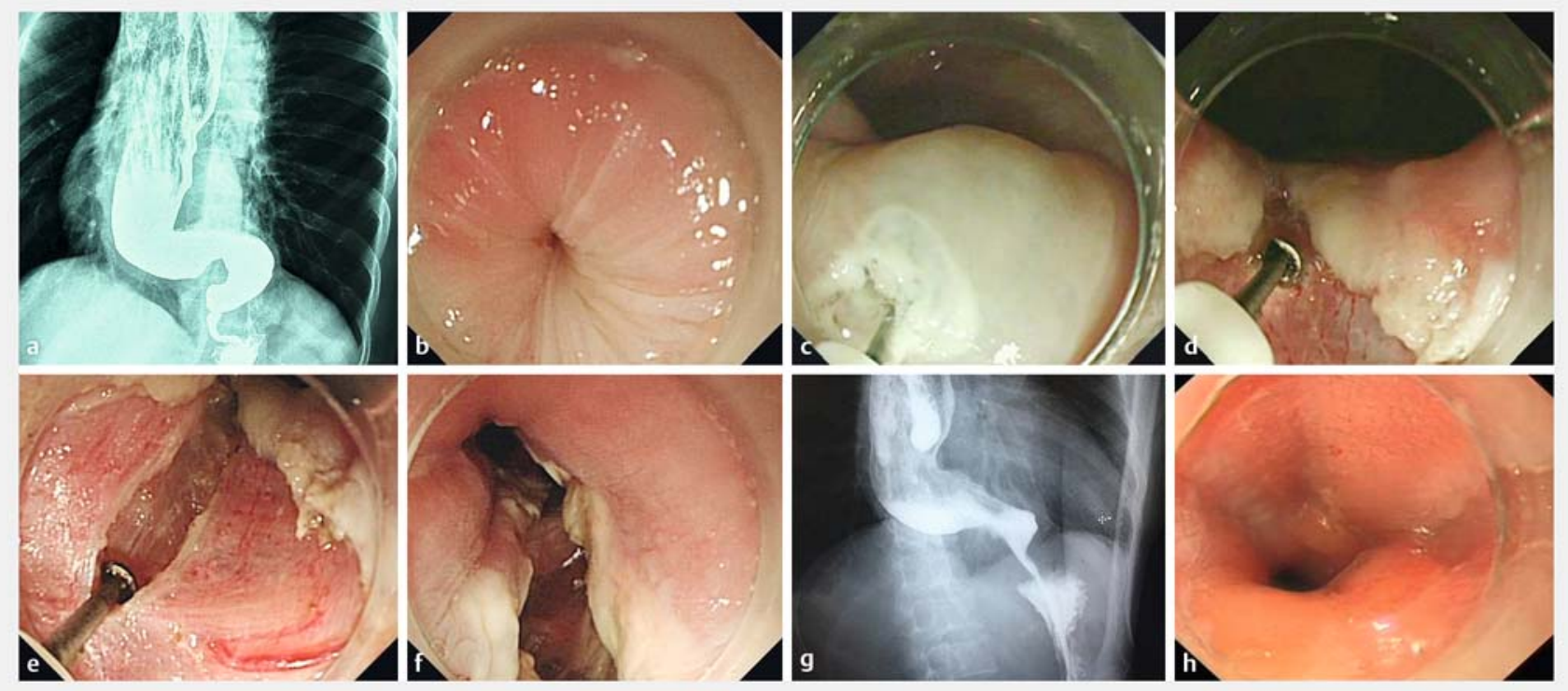

- Fig. 1 Open peroral endoscopic myotomy (O-POEM). a Preoperative barium radiograph showing the beak-shaped appearance of a distal esophagus (sigmoid-shaped esophagus). b Preoperative gastroscopy showing a tightly closed cardia. c, d Mucosotomy performed after submucosal saline injection. e Cutting of a circular layer of the esophagus after mucosectomy. $\mathbf{f}$ Postoperative gastroscopy with a relaxed cardia (greatly improved compared with the tight esophagogastric junction with lumen effacement seen in $\mathbf{b}$ ). $\mathbf{g}$ Postoperative barium radiograph showing rapid passage of barium from the esophagus into the stomach. $\mathbf{h}$ Gastroscopic view of the postoperative cardia during follow-up revealed a healing mucosa in the area of O-POEM.

A 54-year-old woman sought clinical consultation because of a $>27$-year history of dysphagia. She had an Eckardt score of 13 and was diagnosed with sigmoid-type achalasia (S2 type, type II) based on esophageal motility testing, upper endoscopy, barium esophagography, and clinical presentations.

We investigated a technique of peroral endoscopic myotomy (POEM) performed directly without a submucosal tunnel for the treatment of achalasia, which we call open POEM (O-POEM). O-POEM was successfully performed with no procedurerelated adverse events, resulting in a post O-POEM Eckardt score of 2 ( $\mathbf{F i g . 1 ,}$ - Video 1). The procedure time for O-POEM was 25.0 minutes and the length of the myotomy was $8.0 \mathrm{~cm}$. Prophylactic antibiotics were given intravenously 30 minutes before O-POEM, and a nasogastric tube placement was continued for 2 days postoperatively. A

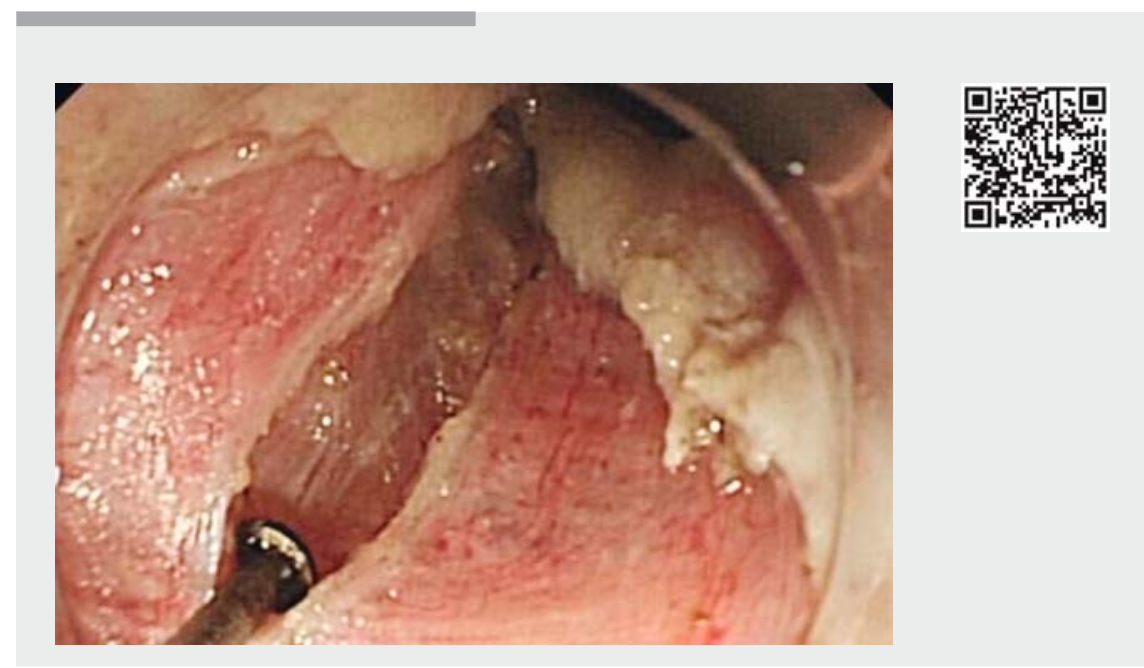

$\checkmark$ Video 1 Preoperative gastroscopy showing a dilated and tortuous esophageal lumen (S2 type) with a tightly closed cardia. A submucosal injection and mucosal incision were performed, followed by the selective myotomy of the circular muscle. After complete myotomy, smooth passage of the endoscope through the esophagogastric junction was possible with minimal resistance. 
liquid diet was allowed at postoperative Day 3, and then this patient was fit for discharge.

A regular diet was allowed at postoperative Day 10 and her symptoms resolved completely during the follow-up of 1 month. A reduction of lower esophageal sphincter pressure and a timed barium esophagogram were observed during follow-up 1 month later. The follow-up endoscopy performed for the patient 1 month later revealed healing mucosa in the area of O-POEM.

POEM has become an established modality for achalasia because of its high feasibility and efficacy. However, the POEM procedure is based on endoscopic myotomy using the submucosal tunnel as an operating space, which is highly demanding technically. Implementation of new technology in achalasia is a challenge for endoscopic treatment, especially when it comes to complex achalasia with a sigmoid-shaped esophagus (S2 type) [1,2], because the dilated and tortuous esophageal lumen may make subsequent endoscopic dissection and separation of tissue planes difficult; thus, endoscopic treatment for advanced achalasia with sigmoid-type esophagus is still challenging. This O-POEM technique takes advantage of the POEM procedure to achieve selective myotomy of the circular muscle, and the remarkable capacity of the esophageal epithelial cells for tissue repair and wound healing $[3,4]$.

$\mathrm{O}$-POEM is a feasible and effective endoscopic treatment modality for achalasia with sigmoid-shaped esophagus. The O-POEM procedure for the treatment of achalasia is easier and less time- consuming than POEM. The short-term outcome of O-POEM for achalasia with sigmoid-shaped esophagus is excellent, with short-term symptom relief in the current case without any complications. However, further randomized controlled clinical trials are needed to focus on the question of whether or not this technique has the potential to replace traditional POEM for achalasia with sigmoidtype esophagus.

Endoscopy_UCTN_Code_TTT_1AQ_2AF

\section{Competing interests}

None

\section{The Authors}

Wei Liu", Ling Liu", Hong-Lin Chen, Hong-Ze Zeng, Chun-Cheng Wu, Lian-Song Ye, Bing Hu Department of Gastroenterology, West China Hospital, Sichuan University, Chengdu, Sichuan, P.R. China

\section{Corresponding author}

\section{Bing Hu, MD}

Department of Gastroenterology, West China Hospital, Sichuan University, No. 37 Guo Xue Xiang, Chengdu, Sichuan, 610041, P.R. China

Fax: +86-028-85423387

hubingnj@163.com

* These authors contributed equally to this paper.

\section{References}

[1] Zhou PH, Li QL, Yao LQ et al. Peroral endoscopic remyotomy for failed Heller myotomy: a prospective single-center study. Endoscopy 2013; 45: $161-166$

[2] Hu JW, Li QL, Zhou PH et al. Peroral endoscopic myotomy for advanced achalasia with sigmoid-shaped esophagus: long-term outcomes from a prospective, single-center study. Surg Endosc 2015; 29: 2841 - 2850

[3] Akintoye E, Kumar N, Obaitan I et al. Peroral endoscopic myotomy: a meta-analysis. Endoscopy 2016; 48: 1059-1068

[4] Barbera M, di Pietro M, Walker E et al. The human squamous oesophagus has widespread capacity for clonal expansion from cells at diverse stages of differentiation. Gut 2015; 64: $11-19$

\section{Bibliography}

DOI https://doi.org/10.1055/s-0043-119411

Published online: 9.10.2017

Endoscopy 2017; 49: E311-E312

(c) Georg Thieme Verlag KG

Stuttgart · New York

ISSN 0013-726X

\section{ENDOSCOPY E-VIDEOS}

https://eref.thieme.de/e-videos

回屌 Endoscopy E-Videos is a free 留 自触: on interesting cases and new techniques in gastroenterological endoscopy. All papers include a high quality video and all contributions are freely accessible online.

This section has its own submission website at https://mc.manuscriptcentral.com/e-videos 